\title{
Mean Thickness
}

National Cancer Institute

\section{Source}

National Cancer Institute. Mean Thickness. NCI Thesaurus. Code C120721.

The arithmetic mean of a range of values that describe the thickness of an entity. 